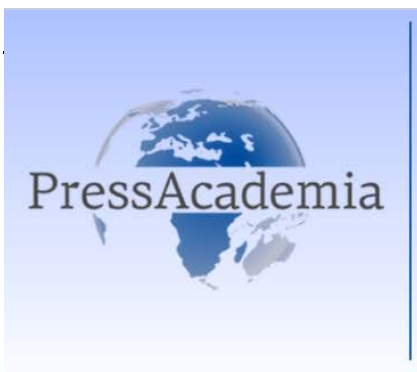

Press Academia Procedía

Global Business Research Congress (GBRC), May 26-27, 2016, Istanbul, Turkey.

\title{
DETERMINING DIFFERENCES BETWEEN MARKETING STRATEGY ATTITUDES OF EXPORTING AND NOT EXPORTING FIRMS DURING CRISIS AND HOW THEY ARE AFFECTED
}

\section{DOI: 10.17261/Pressacademia.2016118640}

Mahmut Baydas

Necmettin Erbakan University. mbaydas@konya.edu.tr

\begin{abstract}
As it is known the most essential external environment element threatining the existence of the firms is crisis fact. Firms should find right reactions to overcome the crisis they face. There is a need to develop pro active strategies before and after the crisis to be less affected or even to get advantage from it. Establishing an effective crisis management, determining "accurate marketing strategies" in addition to preparing crisis action plan, changing these strategies (if necessary) are one of these pro active strategies. First aim of this study is determing the relation between how firms are affected from the crisis and their level of income, size and export. Second aim is to determine differences between marketing strategies of exporting and not exporting firms during crisis. In direction of these aims, questionarre method was applied to the managers of the number of 412 small, medium and large scale furniture firms in Istanbul, and the results were statistically analyzed. According to the final results, the exporting and high level of income firms are less affected from the crisis. On the other hand, it is observed that there are differences between the marketing strategies of exporting and not exporting firms during the crisis.
\end{abstract}

Keywords: crisis management, marketing strategies, export, growth strategies

JEL Codes: M30, M20, M10

\section{IHRACAT YAPAN VE YAPMAYAN IŞLETMELERIN KRIZDEN ETKILENME VE KRIZ DÖNEMINDE PAZARLAMA STRATEJILERI TUTUMLARI ARASINDAKI FARKLILIĞIN BELIRLENMESI}

\section{ÖZET}

Bilindiği gibi işletmelerin varlığını tehdit eden en önemli dış çevre unsuru kriz olgusudur. İşletmeler karşı karşıya kalındığında krizleri yapacakları doğru hamlelerle aşmak zorundadırlar. Kriz öncesi ve sonrası dönemlerde işletmelerin, krizden daha az etkilenmeleri hatta krizi fırsata çevirebilmeleri için pro-aktif stratejiler geliştirmeleri gerekmektedir. Etkin bir kriz yönetimi sağlama, kriz eylem planları hazırlamanın yanında 'doğru pazarlama stratejileri' saptama, gerekirse bu stratejileri değiştirmek bunlardan bazılarıdır. Bu çalışmadaki birinci amaç işletmelerin gelirler düzeyleri, büyüklükleri ve ihracat yapmaları ile krizden etkilenmeleri arasındaki ilişkiyi belirlemektir. Diğer amaç ise ihracat yapan ve yapmayan işletmelerin kriz döneminde uyguladıkları pazarlama stratejileri arasındaki farklııkların belirlenmesidir. Araştırmanın amaçları doğrultusunda İstanbul'da faaliyet gösteren küçük, orta ve büyük ölçekli mobilya işletmeleri yöneticilerinin görüşleri anket yöntemiyle araştırmaya dahil edilerek 412 işletme yöneticisinin görüşleri istatistiksel yöntemlerle analiz edilmiştir. Elde edilen sonuçlara göre gelir düzeyi yüksek, ihracat yapan büyük işletmeler krizlerden daha az etkilenmektedirler. Öte yandan ihracat yapan ve yapmayan işletmelerin kriz dönemlerinde uyguladıkları pazarlama stratejilerinde farklılıklar olduğu görülmüştür .

Anahtar Kelimeler: Kriz Yönetimi, pazarlama stratejileri, ihracat, büyüme stratejileri Jel Kodları: M30, M20, M10 


\section{GiRiş}

Krizler doğası gereği beklenmeyen ,önceden sezilmesi zor, dış çevreden gelen bir tehdit olması özelliğiyle ekonomik, siyasi ,finansal ,doğal afetler gibi pek çok türleri içinde barındırmaktadır .İşletmeler bu yönüyle kriz riskini önceden kontrol edememekte başka bir ifadeyle gelişine engel olamamaktadır .Şiddetli kriz dalgaları işletmeleri iflasa kadar götürebilmektedir. Öte yandan kontrol edilemeyen bir risk türü olsa da krizler, önceden hazırlanan eylem planları ve uygulanacak stratejilerle fırsata bile dönüşebilmektedir. .Normal dönemlerde bazen elde edilemeyecek kazanımlar doğru karar,eylem ve stratejilerle kriz dönemlerinde elde edilebilmektedir. İşletmeler normal dönemlerinde çalışıp çabaladıklarının çok daha fazlasını kriz dönemlerinde yaparlar. Çünkü ortada adeta bir varlık yokluk savaşı vardır . İşletmeler krizi minumum hasarla kapatmak veyahut durumu fırsata çevirebilmek için daha stratejik davranırlar. Stratejik tutum daha çok alınan kararlarda kendisini gösterir. İşletmenin hemen hemen tüm departmanları gibi pazarlama departmanı da kriz dönemlerinde daha çok giderleri kısma tutumu geliştirir. Bu işletmelerin kriz tehdidine karşı geliştirdikleri bir savunma mekanizmasıdır . İşletmeler kazançlarını ve firma değerlerini maksimize etmek için pek çok strateji uygularlar. Pazarlama departmanı da kendisine düşen yönü itibariyle bazı stratejiler uygulamaktadır . Büyüme ,pazar payı ,rekabetçi ,maliyeti düşürme ,müşteri kazanma stratejileri gerek normal gerek kriz dönemlerinde uygulanabilen pazarlama stratejileri olarak sayılabilir ( Kaşlı , 2009: 91 ; Öztürk ve Türkmen, 2006: 77).Doğru pazarlama stratejisini belirlemek özellikle kriz dönemleri için çok önemlidir. Bu karar verilirken işletmenin kriz öncesi ve sonrası durumu, gelir seviyesi ,büyüklük yapısı ve ihracat yapıp yapmaması gibi aslında pek çok faktörün de dikkate alınması gerekmektedir .Bu çalışmada ise krizden etkilenmede işletmelerin gelir ,büyüklük ,ihracat yapıp yapmama durumunun etkisi incelendikten sonra sonra ihracat yapan ve yapmayan işletmelerin kriz dönemlerinde uyguladıkları pazarlama stratejileri arasındaki farklııı belirlenmeye çalışılmıştır .

Araştırmanın amacı doğrultusunda aşağıda sıralanan hipotezler geliştirilmiştir:

H1: İşletmelerin gelir düzeyleri ile krizden etkilenmeleri arasında ilişki bulunmaktadır.

H2: İşletmelerin büyüklükleri ile krizden etkilenmeleri arasında ilişki bulunmaktadır.

H3: İşletmelerin ihracat yapmaları ile krizden etkilenmeleri arasında ilişki bulunmaktadır.

H4: İhracat yapan veya yapmayan işletmelerin kriz dönemlerinde uyguladıkları pazarlama stratejileri arasında farklılık vardır.

\section{KRIZ VE KRIZ YÖNETIMi}

TDK sözlüğüne göre kriz kelimesi köken olarak fransızca 'crise' kelimesine dayanmaktadır. Kriz için yapılan belli başlı tanımlar şöyledir : Bir organda birdenbire ortaya çıkan fizyolojik bozukluk, akse ; bir kimsenin yaşamında görülen ruhsal bunalım ; bir şeyin çok kıt bulunması durumu ;bir şeye duyulan ani ve aşırı istek ; ekonomik çöküntü ; bir ülkede veya ülkeler arasında, toplumun veya bir kuruluşun yaşamında görülen güç dönem, bunalım, buhran. ( http://www.tdk.gov.tr/)

Kriz, işletmeler için risklerin, tehditlerin ve belirsizliklerin arttığı, rutin faaliyetlerin devam ettirilemediği ve daha hızlı iyileştirmelerin gerektiği bir süreç olarak ifade edilebilir (Erdoğan, 2003: 6)

Krizi ortaya çıkaran çok çeşitli faktörler vardır. Kriz oluşumunda etkili olan faktörler, dış ve iç faktörler olmak üzere ikiye ayrılır. İşletmelerin dış çevresinde etkili olan genel nitelikte pek çok faktör vardır. Bunların sınırlarını belirlemek oldukça zordur. Dış çevre faktörleri iç çevre faktörlerinden daha fazla krizlere neden olabilmektedir (Aydın, 2011: 42) .

Kriz, her işletmenin yaşamında karşılaşabileceği bir durumdur. Bu nedenle yöneticilerin krize karşı daima hazırıklı olması gerekir. Yönetim becerisi, risk ve kriz anlarında ayrı bir önem kazanır. Her şeyin normal ve yolunda gittiği durumlarda yönetim becerileri çok belirgin değildir. Kriz yönetimi, yönetimin önemli bir boyutunu oluşturmaktadır. Kriz yönetimi becerisine sahip olmayan işletmelerin ayakta kalmalarını beklemek doğru değildir (Demirtaş, 2000: 355).

Kriz yönetimi, olası kriz durumuna karşılık, kriz sinyallerinin alınarak değerlendirilmesi ve örgütün kriz durumunu en az kayıpla atlatabilmesi için gerekli önlemlerin alınması ve uygulanması sürecidir. Kriz yönetiminin 
temel amacı, örgütü kriz durumlarına hazırlamaktır. Kriz yönetim süreci beş aşamada incelenebilir(Can, 2002: 337-340):

1. Kriz sinyallerinin alınması

2. Krize hazırlık ve korunma

3. Krizin denetim altına alınması

4. Normal duruma geçiş

5. Öğrenme ve değerlendirme.

Şekil 1: Kriz Yönetim Süreci

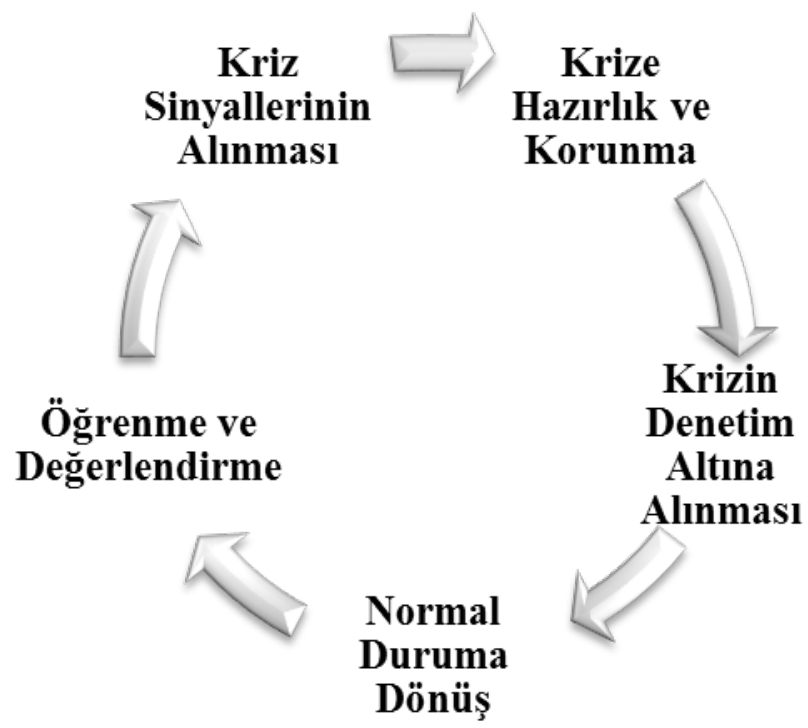

Kaynak: Can, 2002: 339

Augustine (2000: 17-39) ise kriz yönetim sürecini, krizden kaçınmak, krizi yönetmeye hazırlanmak, krizi saptamak, krizi dondurmak, krizi çözmek ve krizden yarar sağlamak olarak altı aşamada açıklamaktadır.

\section{PAZARLAMA VE PAZARLAMA STRATEJILERI}

Pazarlamanın rolü, hedef pazardaki tüketicinin değişen istek ve ihtiyaçlarını tanımlamak, tüketiciye en iyiyi sunabilmek için pazarlama stratejilerini dizayn etmek ve böylece pazarlama amaçlarına ulaşabilmektir (Yükselen, 1990: 31).

Şekil 2: Pazarlama Yönetim Süreci

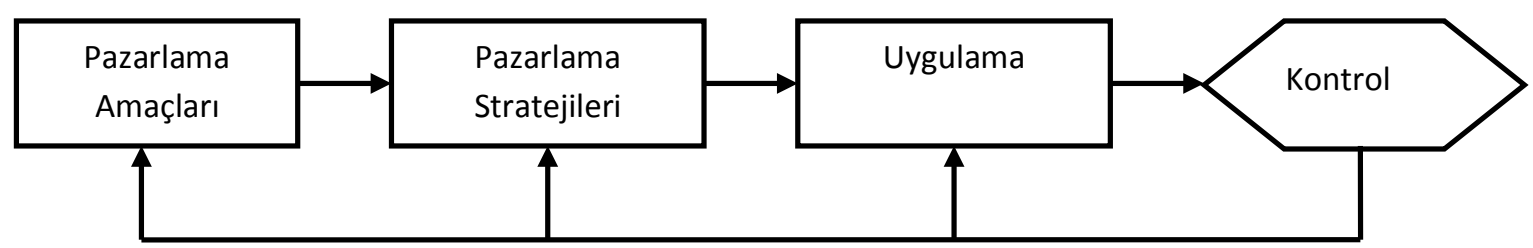

Kaynak: Torlak, Ö. v, 2006: 298: Kotler, J. Saunders, G. Armstrong,ve V. Wong, (1996). Principles of Marketing, TheEuropean Edition, PrenticeHall. 
Pazarlama stratejisi, pazarlama hedeflerine ulaşmak için benimsenen bir pazarlama mantığı veya politikası olarak tanımlanabilir. Pazarlama stratejisi, hedef pazar, pazarlama karması ve pazarlama giderleri gibi konuların koordinasyonundan ibarettir (Cemalcılar, 1994: 315).

Pazarlama stratejisi belirlenirken en önemli nokta, beklenen sonuçları elde etmeye ve en fazla faydayı sağlamaya çalışırken mümkün olan en düşük riski üstlenmeye gayret gösterilmesidir. Pazarlama stratejisi geliştirilirken yapılması gereken üç faaliyet söz konusudur. Bunlar, arzu edilen pazar konumunun belirlenmesi (konumlandırma). , büyüme stratejisinin seçimi ve uygun pazarlama stratejisinin seçimidir. Ayrıca pazarlama stratejisini belirlerken işletmenin güçlü yönlerini mümkün olduğunca öne çıkarmak ve zayıf yönlerini ise en düşük seviyede tutmaya özen göstermekte fayda vardır(Torlak ve diğ. , 2006: 305).

Kriz gibi belirsizlik ve durgunluk ortamlarında ise, pazarlama yöneticilerinin hem tüketicileri ellerinde tutabilmeleri hem de kâr elde edebilmeleri için pazarlama strateji ve eylemlerini gözden geçirmeleri bir bakıma gerekirse modifiye etmeleri gerekmektedir. Ancak pazarlama yöneticilerinin krize tepkisi, bunun işletmeleri üzerindeki etkisini ve anlamını nasıl algıladıklarına bağlı olarak değişebilmektedir. Çünkü olası bir kriz farklı işletmeleri farklı şekillerde etkileyebilmektedir (Shama,2003: 62-63).

Gerek normal ve gerekse de mobilya işletmelerinin kriz dönemlerinde uygulayabilecekleri pazarlama stratejileri beş bölümde incelene bilinir. Bu stratejiler; büyüme, pazar payı, rekabetçi, maliyet düşürme, ve müşteri kazanma stratejileri olarak sınıflandırılabilir (Kaşlı,2009: 91, Öztürk ve Türkmen, 2006: 77, Usal ve Oral, 2001; Tek, 1997).

Diğer taraftan çalışmamızda ayırma fonksiyonu olarak araştırılan değerlerden biri olan ihracat, mikro açıdan işletmeler için yerel pazardaki kriz gibi dalgalanmalardan ve yerel rekabetten kaçınmak amacıyla kullanıldığı için önem taşımaktadır.( Torlak Ö. vd ,2007 : 104 ) Bu bağlamda ihracat eksenli geliri yüksek ve büyük işletmelerle ihracat yapmayan geliri düşük ve küçük işletmeler krizden etkilenmeleri ve dolayısıyla uygulayacakları pazarlama stratejileri de farklı olabilir. Bu çalışmada incelenen husus bu farklılığın düzeyini belirlemek ve konuyu değerlendirmektir.

\section{ARAŞTIRMANIN METODOLOJISI}

\section{1. Örnekleme Süreci}

Araştırmanın ana kütlesini İstanbul'da faaliyet gösteren mobilya işletmeleri oluşturmaktadır. Örnek büyüklüğü \%95 güven aralığı ve \%5 hata payı ile 384 olarak belirlenmiştir. Örnekleme yöntemi olarak basit tesadüfi örnekleme kullanılmıştır.

\subsection{Veri Toplama Yöntem ve Aracı}

Araştırmada veriler kapalı uçlu soruların yer aldığı anket yöntemi kullanılarak toplanmıştır. Anket iki grup sorudan oluşmaktadır ve toplam 29 soru yer almaktadır. Anketin birinci soru grubunda, anketi dolduran kişilerin ve temsil ettikleri işletmelerin demografik özelliklerini belirlemeye yönelik 10 soru yer almaktadır. İkinci soru grubunda ise ihracat yapan ve yapmayan işletmelerin uyguladıkları pazarlama stratejilerini belirlemeye yönelik 19 soru yer almaktadır. Bu grupta yer alan soruların tamamı 5'li Likert ölçeğine göre hazırlanmıştır (1: Hiç Katılmıyorum, 2: Katılmıyorum, 3: Kararsızım, 4: Katılıyorum ve 5: Tamamen Katılıyorum).

Anket 450 işletmeye uygulanmıştır. Ancak, çeşitli nedenlerden dolayı 38 anket formu geçersiz kabul edilmiş ve araştırmaya 412 anket formu dahil edilmiştir. Anket çalışması, Haziran 2012 tarihinde İstanbul MODOKO ve MASKO mobilyacılar sitelerinde yapılmıştır.

Verilerin analizinde SPSS istatistik programı kullanılarak ortalamalar, standart sapma, frekans dağılımları, ölçeklerin güvenilirlik katsayısı olan CronbachAlpha, ayırma fonksiyonu olan diskriminant, değişkenler arasındaki ilişkileri saptamak için korelasyon, açıklayıcı faktör ve çoklu regresyon analizleri yapılmıştır. 


\section{VERILERIN ANALIZi}

\subsection{Demografik Özellikler}

Tablo 1. 'de ankete katılan cevaplayıcıların ve temsil ettikleri işletmelerin demografik özellikleri gösterilmiştir.

Tablo 1: Demografik Özellikler

\begin{tabular}{|c|c|c|c|}
\hline & & FREKANS & YÜZDE \\
\hline \multirow[t]{2}{*}{ CINSIYYT } & Kadın & 78 & 18,9 \\
\hline & Erkek & 334 & 81,1 \\
\hline \multirow[t]{5}{*}{ EĞiTiM DURUMU } & ilköğretim & 28 & 6,8 \\
\hline & Lise & 36 & 8,7 \\
\hline & Önlisans & 25 & 6,1 \\
\hline & Lisans & 254 & 61,7 \\
\hline & Lisansüstü & 69 & 16,7 \\
\hline \multirow[t]{3}{*}{ IŞLETMEDEKI KONUM } & İşletme Sahibi & 289 & 70,1 \\
\hline & Departman Müdürü & 123 & 29,9 \\
\hline & Kısım Şefi & 0 & 0 \\
\hline \multirow[t]{8}{*}{ AYLIK CIRO (Gelir). } & 100000 TL'ye Kadar & 90 & 21,8 \\
\hline & $100001-150000$ & 20 & 4,9 \\
\hline & $150001-200000$ & 38 & 9,2 \\
\hline & $200001-250000$ & 66 & 16 \\
\hline & $250001-300000$ & 93 & 22,6 \\
\hline & $300001-350000$ & 48 & 11,7 \\
\hline & $350001-400000$ & 25 & 6,1 \\
\hline & 400001 VE ÜSTÜ & 32 & 7,8 \\
\hline \multirow[t]{2}{*}{ IHRACAT } & Evet & 266 & 64,6 \\
\hline & Hayır & 146 & 35,4 \\
\hline \multirow[t]{2}{*}{ IŞ̧LTME BÜYÜKLÜĞÜ } & $\begin{array}{l}\text { Küçük ve Orta Ölçekli } \\
\text { İşletme }\end{array}$ & 385 & 93,4 \\
\hline & Büyük Ölçekli Işletme & 27 & 6,6 \\
\hline \multirow[t]{4}{*}{ IŞLETME YAPISI } & Kendi Markası & 72 & 17,5 \\
\hline & Fason Imalat & 120 & 29,1 \\
\hline & $\begin{array}{l}\text { Hem Kendi Markası Hem } \\
\text { de Fason İmalat }\end{array}$ & 76 & 18,4 \\
\hline & Bayi/ Franchisee & 144 & 35,0 \\
\hline \multirow[t]{5}{*}{ IŞLETME FAALIYET ALANI } & Mutfak/Banyo Mobilya & 43 & 10,4 \\
\hline & Aksesuar/Aydınlatma & 33 & 8,0 \\
\hline & Büro/Metal Mobilya & 72 & 17,5 \\
\hline & Ev Mobilyası & 211 & 51,2 \\
\hline & Bebek/Genç Mobilya & 28 & 6,8 \\
\hline \multirow[t]{2}{*}{$\begin{array}{l}\text { DAHA ÖNCE } \\
\text { ETKILENME }\end{array}$} & Evet & 410 & 99,8 \\
\hline & Hayır & 2 & 0,2 \\
\hline
\end{tabular}

Yukarıdaki demografik bulgular cevaplayıcının çoğunlukla erkek, üniversite mezunu, işletme sahibi, işletmesi ihracat yapan, işletmesi daha önce bir krizden etkilenmiş ve işletmesinin büyüklük olarak KOBi sınıfında olduğunu bize göstermektedir. 


\section{2. İ̧̧letmelerin Gelirler Düzeyleri, Büyüklükleri ve İhracat Yapmaları ile Euro Bölgesi Krizinden Etkilenmeleri Arasındaki ilişki}

İşletmelerin gelirler düzeyleri, büyüklükleri ve ihracat yapıp yapmamaları ile Euro Bölgesi Krizinden etkilenmeleri arasında ilişki olup olmadığı incelenmiş ve korelasyon analizi yapıımıştır. Analiz sonuçları Tablo 3. 10 'da gösterilmiştir.

Tablo 2: İşletmelerin Gelirler Düzeyleri, Büyüklükleri ve İhracat Yapma ile Euro Bölgesi Krizinden Etkilenmeleri Arasındaki ilişski

\begin{tabular}{|l|l|c|c|c|}
\hline $\begin{array}{l}\text { Gelir, Büyüklük ve Ihracat yapmaEuro } \\
\text { Bölgesi Krizinden Etkilenme }\end{array}$ & $\begin{array}{c}\text { İşletmenin Gelir } \\
\text { Düzeyi }\end{array}$ & $\begin{array}{c}\text { İşletme } \\
\text { Büyüklüğü }\end{array}$ & Ihracat Yapma \\
\hline $\begin{array}{l}\text { Euro Bölgesi } \\
\text { Krizinden }\end{array}$ & Korelasyon & $-0,524^{* *}$ & $-0,220^{* *}$ & $-0,202^{* *}$ \\
Etkilenme & $\mathrm{P}$. & 0,000 & 0,000 & 0,000 \\
& $\mathrm{~N}$ & 412 & 412 & 412 \\
\hline
\end{tabular}

$* *: p<0,01$

İşletmelerin gelirler düzeyleri, büyüklükleri ve ihracat yapıp yapmamaları ile Euro bölgesi krizinden etkilenmeleri arasındaki ilişkiye bakıldığında, işletmenin gelir düzeyi $(-0,524)$, , büyüklüğü $(-0,220)$. ve ihracat yapma $(-0,202)$. arasında negatif yönlü anlamlı bir ilişki olduğu görülmektedir. Yani gelir düzeyi yüksek, ihracat yapan büyük işletmeler Euro bölgesi krizinden daha az etkilenmektedirler. Bu durumda;

H1: İşletmelerin gelir düzeyleri ile Euro bölgesi krizinden etkilenmeleri arasında ilişki bulunmaktadır,

H2: İşletmelerin büyüklükleri ile Euro bölgesi krizinden etkilenmeleri arasında ilişki bulunmaktadır,

H3: İşletmelerin ihracat yapmaları ile Euro bölgesi krizinden etkilenmeleri arasında ilişki bulunmaktadır, hipotezleri kabul edilmiştir.

\section{5 . 3 . Ihracat Yapan ve Yapmayan İşletmelerin Kriz Döneminde Uyguladıkları Pazarlama Stratejileri Arasındaki Farklılıkların İncelenmesi}

İhracat yapan ve yapmayan işletmelerin kriz döneminde uyguladıkları pazarlama stratejileri arasında farklılık olup olmadığını görmek amacıyla çoklu ayırma analizi yapılmıştır. İşletmelerin ihracat yapıp yapmamaları kriter değişkenini, kriz dönemi pazarlama stratejileri ise tahmin değişkenini oluşturmuştur. Tablo 4.3. 'de analiz sonucu elde edilen Wilk'sLambda Değerleri ile Öz Değerler gösterilmiştir.

Tablo 3: Kanonik Ayırma Fonksiyonu, Wilks' Lambda Değerleri ve Öz Değerler

\begin{tabular}{|l|l|l|l|l|}
\hline Fonksiyon & Özdeğer & Varyans\% & Kümülâtif\% & $\begin{array}{l}\text { Kanonikal } \\
\text { Korelâsyon }\end{array}$ \\
\hline 1 & 0,212 & 100,0 & 100,0 & 0,143 \\
\hline
\end{tabular}

\section{Wilks' Lambda}

\begin{tabular}{|l|l|l|l|l|}
\hline FonksiyonTesti & Wilks'Lambda & Ki-Kare & df & AnlamlılıkDüzeyi \\
\hline 1 & 0,979 & 81,450 & 5 & 0,000 \\
\hline
\end{tabular}

Tablo 3.'de görüldüğü gibi, kanonikal ayırma fonksiyonları, toplam varyansın \% 100'ünü açıklamaktadır. Fonksiyonun kanonikal korelâsyonu 0, 143'dür. Wilk'sLambda değeri 0, 000 anlamlılık düzeyinde 0, 979'dur. Fonksiyonun değerinin istatistikî bakımdan anlamlı olduğu görülmektedir. Tablo 3. 11. 'de Yapı Matrisi yer almaktadır. 
Tablo 4: Yapı Matrisi

\begin{tabular}{|l|c|}
\hline Kriz Dönemi Pazarlama Stratejileri & Fonksiyon \\
\cline { 2 - 2 } & $\mathbf{1}$ \\
\hline Büyüme Stratejisi & $\mathbf{0 , 5 6 5}$ \\
\hline Pazar Payı Stratejisi & $\mathbf{0 , 4 9 7}$ \\
\hline Rekabetçi Strateji & $-0,465$ \\
\hline Müşteri Kazanma Stratejisi & 0,324 \\
\hline Maliyeti Düşürme Stratejisi & 0,206 \\
\hline
\end{tabular}

Tablo 4. 'de bulunan değişkenler mutlak değerleri göz önüne alınarak incelendiğinde, büyüme stratejisi, pazar payı stratejisi, rekabetçi strateji ve müşteri kazanma stratejisi değişkenlerinin ayırma gücüne sahip oldukları görülmektedir. Bu değişkenlerden hangilerinin istatistikî anlamda ayırmada önemli olduklarının belirlenmesi için Wilks' Lambda, F testi ile kontrol edilmiş ve sonuçları Tablo 5. 'de gösterilmiştir.

Tablo 5: Grup Ortalamaları Eşitliği Testi

\begin{tabular}{|l|c|c|c|c|c|}
\hline $\begin{array}{l}\text { Kriz Dönemi Pazarlama Stratejileri } \\
\text { Değişkenleri }\end{array}$ & $\begin{array}{c}\text { Wilks' } \\
\text { Lambda }\end{array}$ & F & df1 & df2 & $\begin{array}{c}\text { Anlamlılık } \\
\text { Düzeyi }\end{array}$ \\
\hline Büyüme Stratejisi & 0,995 & 1,858 & 1 & 410 & 0,000 \\
\hline Pazar Payı Stratejisi & 0,995 & 2,120 & 1 & 410 & 0,146 \\
\hline Rekabetçi Strateji & 1,000 & 0,134 & 1 & 410 & 0,714 \\
\hline Müşteri Kazanma Stratejisi & 0,993 & 2,739 & 1 & 410 & 0,000 \\
\hline Maliyeti Düşürme Stratejisi & 0,999 & 0,366 & 1 & 410 & 0,099 \\
\hline
\end{tabular}

Tablo 5.'de görüleceği gibi büyüme stratejisi ve müşteri kazanma stratejisi değişkenleri 0,01 anlamlılık düzeyinde ayırma gücüne sahiptirler. Bununla birlikte pazar payı stratejisi, rekabetçi strateji ve maliyeti düşürme stratejisi değişkenlerinin istatistiki bakımdan ayırma gücüne sahip olmadıkları belirlenmiştir.

Tablo 6. 'da anlamlı çıkan değişkenlerin gurup ortalamaları verilmiştir.

Tablo 6: Grup Ortalamaları

\begin{tabular}{|l|c|c|}
\hline Kriz Dönemi Pazarlama Stratejileri Değişkenleri & ihracat Yapanlar & ihracat Yapmayanlar \\
\hline Büyüme Stratejisi & 3,7566 & 2,6524 \\
\hline Müşteri Kazanma Stratejisi & 4,1485 & 3,3694 \\
\hline
\end{tabular}

Tablo 6.'da yer alan ortalamalara göre, ihracat yapan işletmeler, ihracat yapmayan işletmelere oranla büyüme stratejisini ve müşteri kazanma stratejisini daha fazla uygulamaktadırlar. Tablo 7.'de sınıflandırma sonuçları gösterilmiştir.

Tablo 7: Sınıflandırma Sonuçları

\begin{tabular}{|l|l|c|c|c|}
\hline \multirow{4}{*}{} & & \multicolumn{2}{|c|}{ Tahmini Grup Üyeliği } & \multirow{2}{*}{ Toplam } \\
\cline { 2 - 5 } & İşletmelerin Ihracat Durumları & $\begin{array}{c}\text { Ihracat } \\
\text { Yapanlar }\end{array}$ & ihracat Yapmayanlar & 266 \\
\cline { 2 - 5 } & İhracat Yapanlar & 158 & 108 & 146 \\
\cline { 2 - 5 } & İhracat Yapmayanlar & 64 & 82 & $\mathbf{4 1 2}$ \\
\cline { 2 - 5 } & Toplam & $\mathbf{2 2 2}$ & $\mathbf{1 9 0}$ & 100,0 \\
\hline \multirow{2}{*}{$\%$} & İhracat Yapanlar & 59,4 & 40,6 & 100,0 \\
\cline { 2 - 5 } & ihracat Yapmayanlar & 43,8 & 56,2 & \\
\hline
\end{tabular}


Doğru sınıflandırma oranı \% 78, 3. İşletmeleri ihracat yapan ve yapmayan diye ayıran diskriminant fonksiyonuna göre yapılan sınıflandırmada ihracat yapanların 158'i ve ihracat yapmayanların 108'i doğru olarak atanmıştır. Test grubu için doğru sınıflandırma oranı \%78, 3'dür.

Bu sonuçlar göz önünde bulundurulduğunda, ihracat yapan ve yapmayan işletmelerin kriz dönemlerinde uyguladıkları pazarlama stratejilerinde farklııklar olduğu görülmektedir. Bu durumda;

H4: İhracat yapan veya yapmayan işletmelerin uyguladıkları pazarlama stratejileri arasında farklıık vardır, hipotezi kabul edilmiştir.

\section{SONUÇ VE ÖNERILER}

Araştırma sonuçları göstermektedir ki hemen hemen tüm işletmeler daha önce bir kriz yaşamıştır. İşletmelerin gelir düzeyleri, büyüklükleri ve ihracat yapıp yapmamaları ile 'Küresel Krizler'den etkilenmeleri arasında ilişkinin araştırılması sonucunda gelir düzeyi yüksek, ihracat yapan, büyük işletmelerin küresel krizlerden daha az etkilendikleri ortaya çıkmıştır. Bu durum belirli bir seviyenin üstündeki işletmelerin krize karşı daha dirençli olduğu gerçeğini düşündürmektedir. İhracat yapan işletmelerin krizden daha az etkilendikleri gerçeği de krizleri atlatmak ya da fırsata çevirmek isteyen işletmelerce dikkate alınmalıdır.

ìhracat yapan ve yapmayan işletmelerin kriz döneminde uyguladıkları pazarlama stratejileri arasında farklılık olup olmadığını görmek amacıyla yapılan araştırma sonuçlarında ise ihracat yapan işletmeler, ihracat yapmayan işletmelere oranla büyüme stratejisini ve 'müşteri kazanma stratejisi'ni daha fazla uygulamaktadır. 'Müşteri kazanma stratejisi' ihracat yapan ve yapmayan işletmelerin her ikisi için de en yüksek düzeyde katılım gösterilen strateji olması bakımından bu sonuç tahmin edilse de 'büyüme stratejisi'nin kriz dönemlerinde ihracat yapmayan işletmelerce fazla benimsenmediği bilinmektedir. Bu sonuç göstermektedir ki işletmeler kriz dönemlerinde uygulaya geldikleri pazarlama stratejilerini ihracat yapınca değiştirmektedirler. Daha doğru bir ifadeyle uyguladıkları pazarlama stratejilerinin önem ağırıkları bağlamında sıralamasını değiştirmektedirler. Bir bakıma işletmeler ihracat yapınca 'büyüme stratejileri'ne daha fazla önem atfetmekte, işletmelerini bir şekilde büyütme tutumunu takınmaktalardır.

Araştırmanın bulguları iki gerçeği göz önüne sermektedir : 1- kriz dönemlerinde ihracat yapan ve yapmayan işletmelerin uyguladıkları pazarlama stratejileri arasında farkıııklar vardır ; 2- ihracat yapan, geliri yüksek ve büyük işletmeler krizlerden daha az etkilenmektedir. Söz konusu iki bulgu birleştirildiğinde şu öneride bulunabiliriz : krizlere karşı daha dirençli/başarılı bir dinamik oluşturmak isteyen işletmeler, belirli bir seviyede ihracat eksenli olmalı ve 'büyüme stratejileri'ne daha fazla önem vermelidirler.

\section{KAYNAKLAR}

Kaşlı, M. , İlban, O. M. ve ŞAHIN, B. (2009). Modern Pazarlama Stratejileri: AB ve Türk

Turizmi. Elektronik Sosyal Bilimler Dergisi. 8(27), 79-98.

Öztürk Y. ve Türkmen F. (2006). Turizm işletmelerinin Kriz Dönemlerinde Uyguladıkları

Pazarlama Stratejilerine Yönelik Bir Araştırma. Gazi Üniversitesi Ticaret ve Turizm

Eğitim Fakültesi Dergisi . 1, 74-95.

Güncel Türkçe Sözlük ,TDK , http://www.tdk.gov.tr/index.php?option=com gts\&arama=gts\&guid=TDK.GTS.57264b65642584.53854829 (erişim : 30.04.2016)

Erdoğan, A. (2003). Ekonomik Kriz Dönemlerinde Tüketicilerin Gıda Ürünlerini Satın Alma Eğilimleri Üzerine Bir Araştırma, Yayınlanmamış Yüksek Lisans Tezi. Erzurum: Atatürk Üniversitesi. Sosyal Bilimler Enstitüsü

Örnek, A. ve Aydın, Ş. (2011). Kriz ve Stres Yönetimi. Ankara: Detay Yayıncılık

Demirtaş, H. (2000). Kriz Yönetimi. Kuram ve Uygulamada Eğitim Yönetimi Dergisi. 6(23). 353-373.

Can, H. (2002). Organizasyon ve Yönetim. (6. Baskı). Ankara: Siyasal Kitabevi.

Augustıne, N. R. (2000). Önlemeye Çalıştığınız Krizi Yönetmek. Kriz Yönetimi. Salim Atay (Çev). İstanbul: BZD Yayıncılık. 
Yükselen, C. (1990). Enflasyon ve Durgunluk Ortamında Pazarlama Stratejileri ve Küçük İşletmeler Üzerine Bir Araştırma. Pazarlama Dünyası Dergisi. 4(23), 31-39.

Torlak, Ö. , Altunışık, R. , Ve Özdemir Ş. (2006). Modern Pazarlama. Adapazarı: Değişim Yayınları.

Cemalcılar í. (1994). Pazarlama-kavramlar, kararlar, İstanbul : Beta yayınları.

Shama, A. (1993). Marketing StrategiesDuringRecession: A Comparision of Small andLargeFirms. Journal of Small Business Management. $31(3), 62-72$.

Torlak Ö, Özdemir Ş - Kula V. (2007) Türk İşletmelerinin Ihracat Performans Belirleyicleri, Gazi Üniversitesi İktisadi ve idari Bilimler Fakültesi Dergisi 9/1. $103-114$ 